\title{
The economic and productive efficiency on cows fattening projects in Assiut governorate, Egypt
}

\author{
Abd El-Monem A. A. B. , Ismail O. A., Ahmed A. I. M. \\ Agricultural Economics Department, Faculty of Agriculture, Al-Azhar University, Assuit, Egypt
}

\begin{abstract}
The research aims to study the current situation of red meat production in Egypt and especially in Assiut governorate, in addition to assessing the productive and economic efficiency on beef fattening projects and identifying problems facing beef fattening projects in the research sample in Assiut Governorate, Egypt. The research found that the numbers of cattle heads in Egypt have fluctuated between increase and decrease as they reached their maximum level in 2008 with a total number of about 5023.16 thousand while it reached a minimum in 2000 with a total number of about 3526.71 thousand heads, and has taken a general trend Increasing and statistically significant, as the annual increase amount reached about 57,24 thousand heads, as it was found that the number of animals producing red meat in Asyut Governorate has taken an increasing and statistically general trend, as the annual increase amount reached about 5,24 thousand heads. It was also found that the average animal weight when selling varied from one category to another, as it reached in the first, second and third productive category about 355,382 and $393 \mathrm{~kg}$, respectively, and it was also shown that the net acre yield for the third productive category reached about 4299 pounds per head, as it was also shown that it exceeded The return of the invested pound, as it reached about 0.26 pounds per head. With an estimate of the production function of the total research sample, it was found that about $91 \%$ of the production changes are explained by the elements of the total concentrated feed, the weight of the animal when buying, and the total dry feed. Productivity, i.e. an increase in output by a percentage greater than the increase in total resources in a function. There were also significant differences between the net return of the three productive groups, and that the most important problems facing cattle fattening projects are the problem of low net yield followed by the problem of high feed prices, while the problem of high cost of veterinary care came in the last place. Our rrecommendations are:

- Increasing investments directed to the animal production sector.

- Work to provide production requirements at reasonable prices, and support producers to continue the production process.

- Work to provide foreign strains with good genetic traits that are appropriate to the climate conditions in Egypt.

- Benefiting from reclaimed lands in providing the necessary feed for animal production farms.

- Activating the role of veterinary care and farmers' sense of continuous periodic follow-up.
\end{abstract}

Keywords: economic efficiency, production efficiency, production functions.

\footnotetext{
* Corresponding author: Abd El-Monem A. A. B.,

E-mail address: ashraf. abdo@yahoo.com
} 


\title{
الكفاءة الانتاجية و الاقتصادية لمشرو عات تسمين الأبقار في محافظة أسيوط بجمهورية

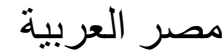

\author{
أشرف عبد النعيم عبد المنعم ، عثمان علي إسماعيل ، أحمد ابر اهيم محمد أحمد \\ قسم الإقتصاد الزر اعي ، كلية الزر اعة ، جامعة الأزهر - فرع أسيوط ، جمهورية مصر العربية
}

يستهدف البحث در اسة الوضع الحالي لإنتاج اللحوم الحمر اء في مصر ومحافظة أسيوط، بالإضافة إلى تقدير الكفاءة الانتاجية والاقتصادية

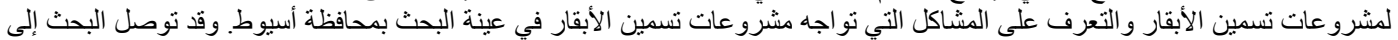

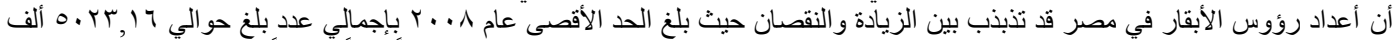

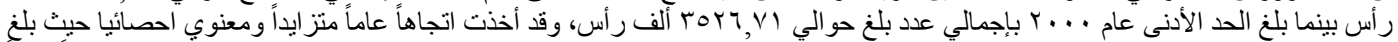

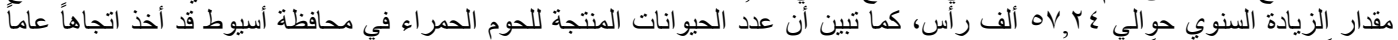

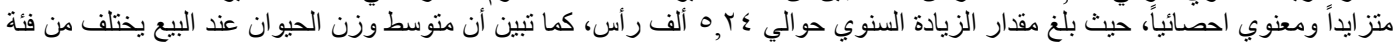

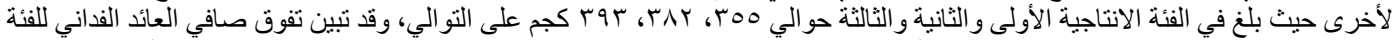

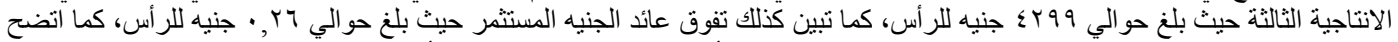

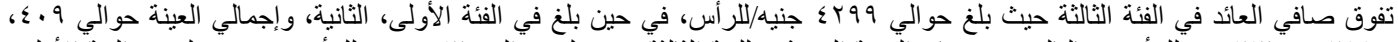

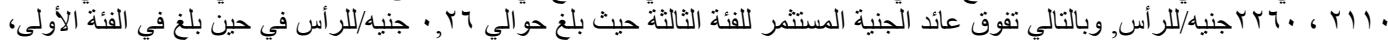

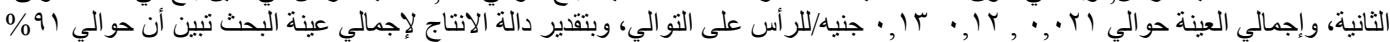

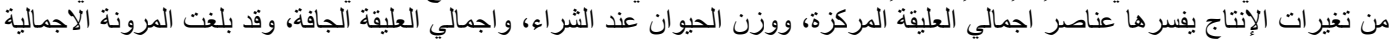

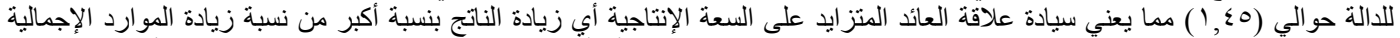

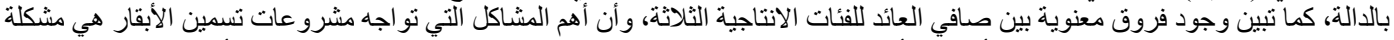
انخفاض صافي العائد تليها مشكلة ارتفاع أسعار الأعلاف بينما جاءت مشكلة ارتفاع تكلفة الرعاية البيطرية التئة في المرتبة الأخيرة. 
o مستوى مصر ومحافظة أسيوط. تقدير الكفاءة الانتاجية والاقتصادية لمشروعات تسمين الأبقار في محافظة أسيوط.

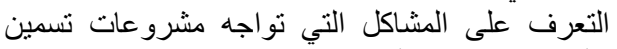
الأبقار في محافظة أسيوط.

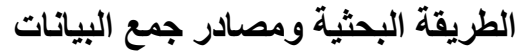

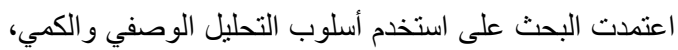

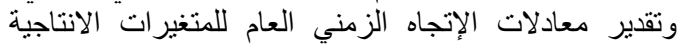

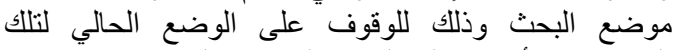

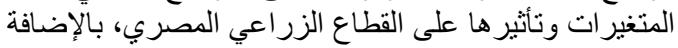

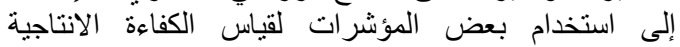

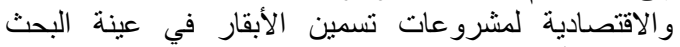
بمحافظة أسيوط. وقد اعتمد البحث على البئ البيانات الإحصائية

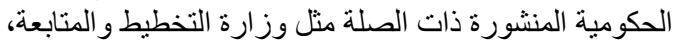

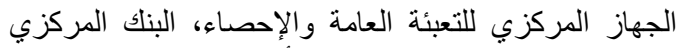

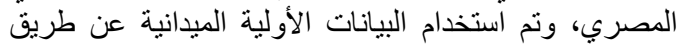

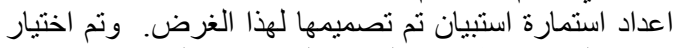

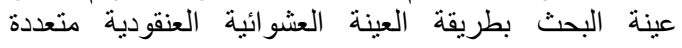

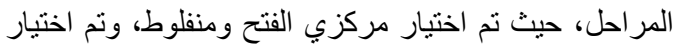

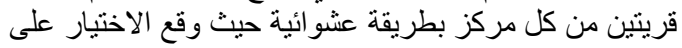

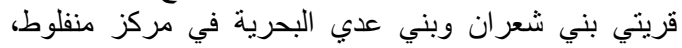

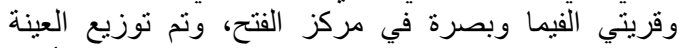

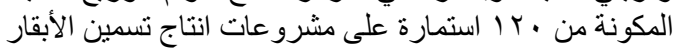

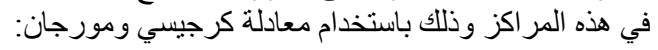

$$
n=\frac{\mathrm{X} 2 \mathrm{NP}(1-\mathrm{P})}{\mathrm{d} 2(\mathrm{~N}-1)+\mathrm{X} 2 \mathrm{P}(1-\mathrm{P})}
$$

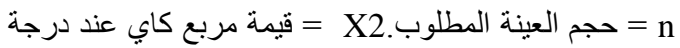

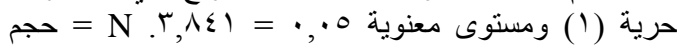

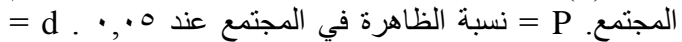

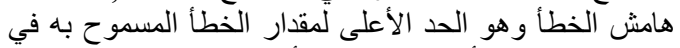

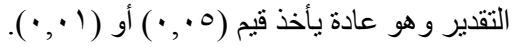

\section{النتائج ومناقشتها}

أولا: تطور أعداد رؤوس الحيوانات المنتجة للحوم الحمراء في مصر ومحافظة أسيوط

1. تطور أعداد رؤوس الحيوانات المنتجة للحوم الحمراء

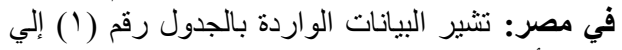

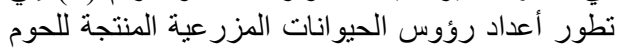

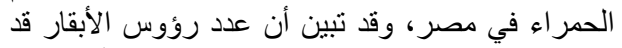
تذبذب بين الزيادة والنقصان حيث بلغ ألغ الحد الأدنى عام الأقرار

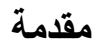

يعد قطاع الانتاج الحيواني ركيزة أساسية من ركائز الانتاج

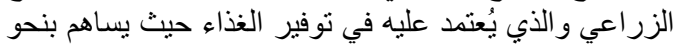

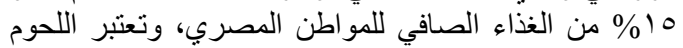

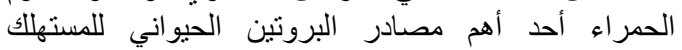

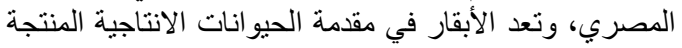

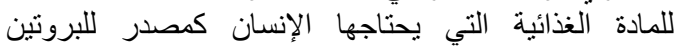

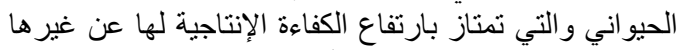

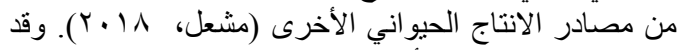

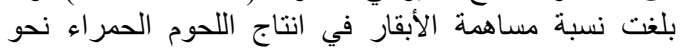

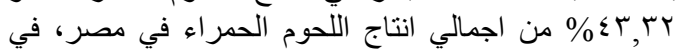

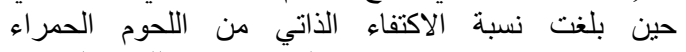

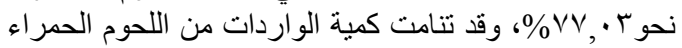

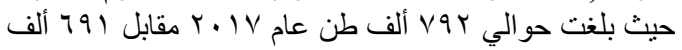

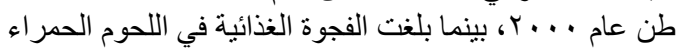

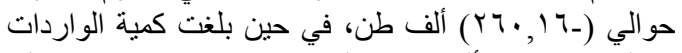

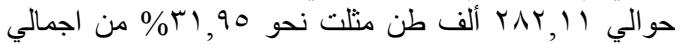

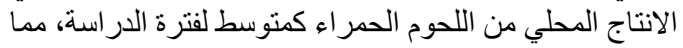

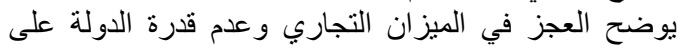

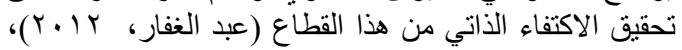

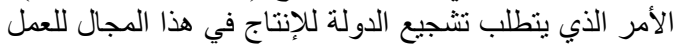

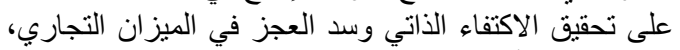

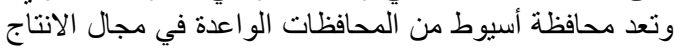

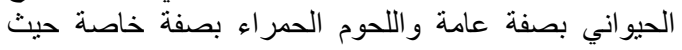

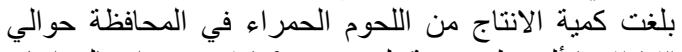

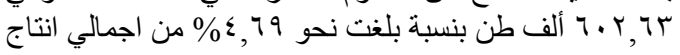

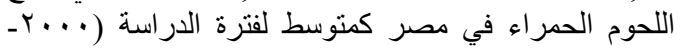
. (r. IV

\section{مشكلة البحث}

نظراً لتز ايد الطلب على البروتين الحيواني و عدم قدرة الانتاج

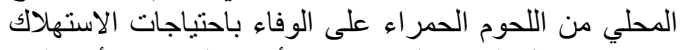

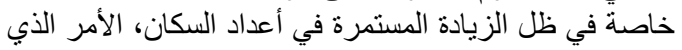

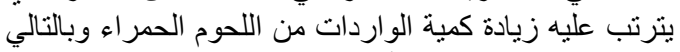

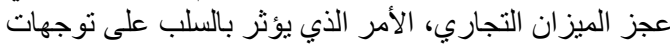

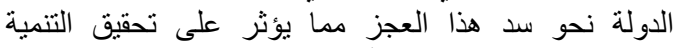

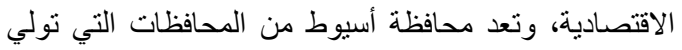

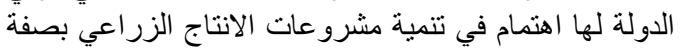

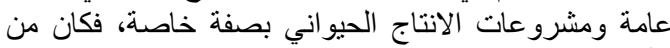
الأهمية دراسة الوضع الحالي لقطاع الانتاج الحيواني في في فئي

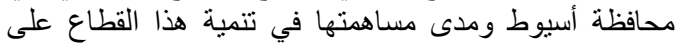
المستوى القومي.

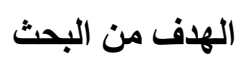
يهدف البحث إلى تحقيق الآتي: 


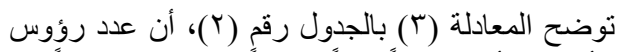

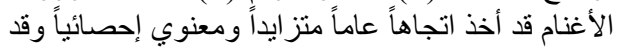

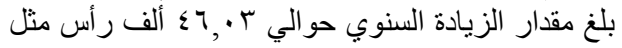

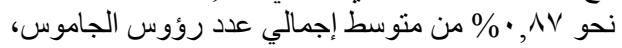

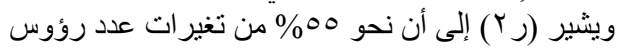

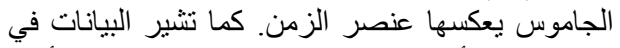

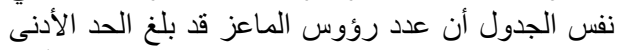

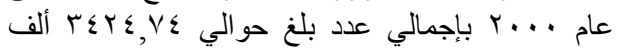

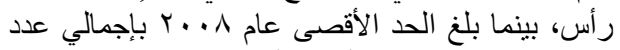

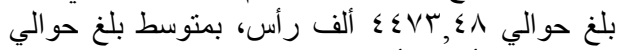

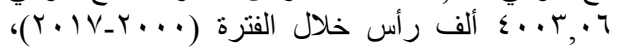

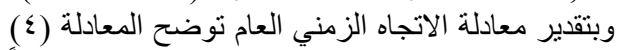

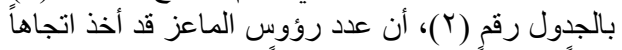

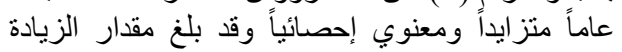

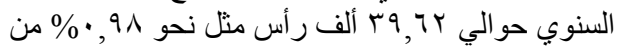

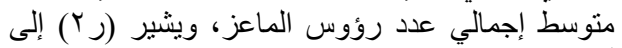

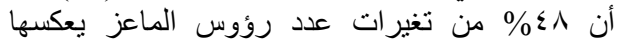

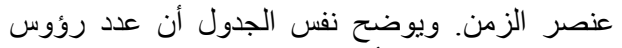

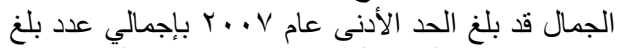

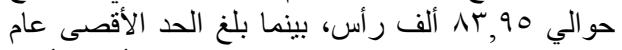

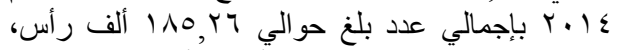

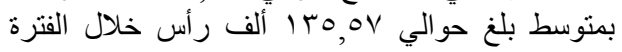

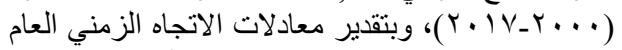

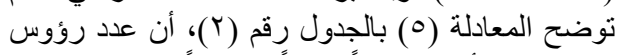

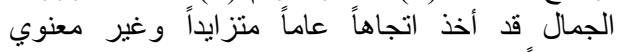

إحصائياً.

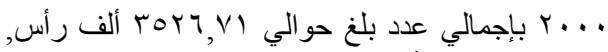

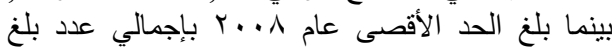

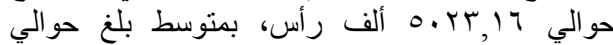

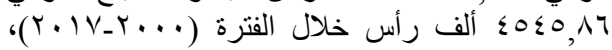

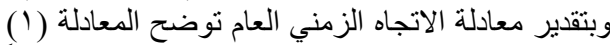

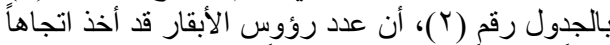

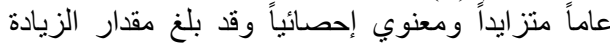

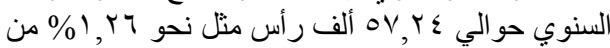

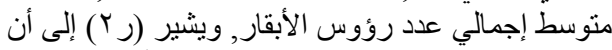

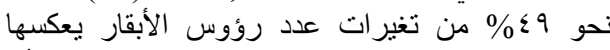

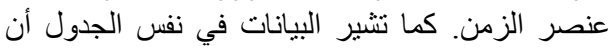

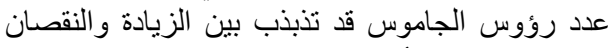

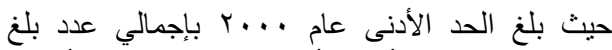

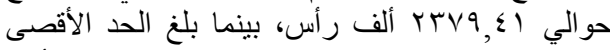

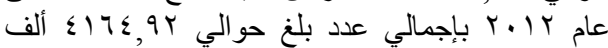

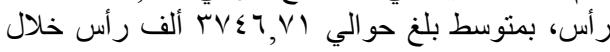

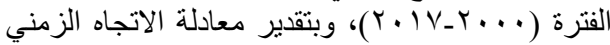

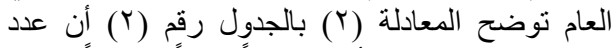

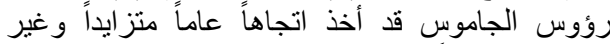

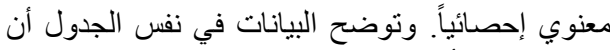

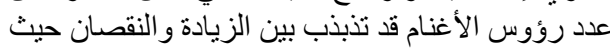

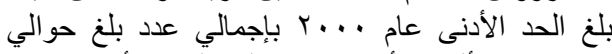

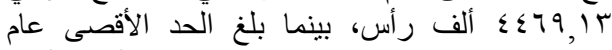

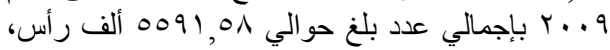

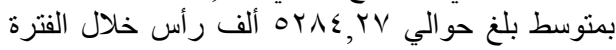

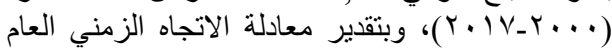

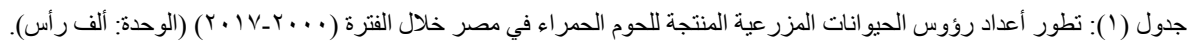

\begin{tabular}{|c|c|c|c|c|c|}
\hline جمال & ماعز & أغنام & جاموس & أبقار & السنة \\
\hline $1 \leqslant \cdot, V \leqslant$ & $r \leqslant Y \leqslant, V \leqslant$ & $\varepsilon \leqslant 79,1 \pi$ & rrVq, $\$ 1$ & rort, (1) & $r \ldots$ \\
\hline ITr,VT & $\Gamma \leqslant 97, V V$ & $\varepsilon T V 1, Y \varepsilon$ & TOTY,Y & $r \Lambda .1, \cdot V$ & $r \ldots l$ \\
\hline$T K V, \cdot A$ & rOAY,Tr & $01 . \varepsilon, 0 Y$ & TVוד, Tr & $\varepsilon \cdot \lambda 1,0 r$ & $r \ldots r$ \\
\hline $1+4, r 1$ & $r \Lambda 1 \cdot, 0 r$ & $\sum 949, .0$ & rVVV,10 & Errq, 99 & $r \ldots r$ \\
\hline $1 \times 9, \leqslant 9$ & rAvq, Ir & $0 . \Sigma r, V V$ & $\Gamma \wedge \leqslant 0,1 \leqslant$ & $\varepsilon r \neg \wedge, 90$ & $r \ldots \varepsilon$ \\
\hline $1 \leqslant r, \varepsilon r$ & $r \Lambda \cdot r, O \Lambda$ & OYTY,P & rA10, $\cdot 9$ & $\varepsilon \leqslant \lambda \leqslant, 70$ & $r \ldots o$ \\
\hline $1 \leqslant \lambda, \mid r$ & $\Gamma \wedge V \vee, \Gamma \leq$ & or $10, \xi 1$ & rqTV,Yr & $\leqslant 7.9, \vee \wedge$ & $r \ldots r$ \\
\hline $1 T, 90$ & $\varepsilon r) \cdot V$ & $0 \leqslant T V, \leqslant 7$ & $\varepsilon 1 \cdot \varepsilon, \lambda 1$ & \&9TY,70 & $r \ldots V$ \\
\hline $1 \cdot V, r V$ & $\varepsilon \leqslant V T, \varepsilon \wedge$ & $0 \leqslant 9 \wedge, \cdot r$ & $\varepsilon .0 Y, T \varepsilon$ & $0 . K T, 17$ & $r \ldots \lambda$ \\
\hline $1 T V, 11$ & $\varepsilon 1 r q, r_{0}$ & 0091,01 & 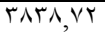 & $\varepsilon 0 Y \leqslant, 90$ & $r \ldots q$ \\
\hline $11.0 \mathrm{~V}$ & $\varepsilon \mid V \leqslant, 91$ & $00 Y 9,0 Y$ & 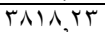 & $\varepsilon V Y \wedge, V Y$ & r.l. \\
\hline $1 Y 7,94$ & $\varepsilon Y \circ \Lambda, I V$ & $0470, \cdot 7$ & rqAr, 17 & $\varepsilon \vee \vee \vee q, \vee \varepsilon$ & $r+11$ \\
\hline $1 \leqslant 1,04$ & $\varepsilon r \cdot \gamma, r_{0}$ & $0 \leqslant Y q, 0 Y$ & हाTE,9Y & 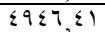 & $r . I T$ \\
\hline $10 r, 9 \leqslant$ & $\sum 10 \%, Y T$ & $007 \varepsilon, 11$ & $r 910, r \leq$ & $\varepsilon V \leqslant \varepsilon, 9 V$ & $r .1 T$ \\
\hline $101, Y 7$ & $\varepsilon 110,19$ & $00 . r, 74$ & rq19,Yq & \&V7Y, $\leqslant 9$ & $r .1 \leq$ \\
\hline 104,01 & $\varepsilon \cdot \Sigma\rceil, Y T$ & $0 \leq 74,17$ & $r v \cdot 1,00$ & $\varepsilon \wedge \lambda r, 19$ & $r .10$ \\
\hline $107.0 \leqslant$ & $\varepsilon r \circ 9, \wedge \tau$ & $0007, \mathrm{KT}$ & $r \leqslant r \neg, \lambda$ & $0 . \mid Y, Y 1$ & $r .17$ \\
\hline 100,11 & rqvr, 79 & $0 \mathrm{O} .0, r \mathrm{r}$ & $r \leqslant r r, O \wedge$ & $\Sigma \Pi \wedge V, \nvdash \wedge$ & $r . I V$ \\
\hline $1 T 0,0 \mathrm{~V}$ & $\varepsilon \ldots r, r$ & $O Y \Lambda \varepsilon, Y V$ & $r V \leqslant 7, V)$ & $\leqslant 0 \leqslant 0, \wedge \uparrow$ & المثتوسط \\
\hline
\end{tabular}

المصدر: الجهاز المركزي للتعبئة العامة والحصاء الكتاب الاحصائي السنوي، أعداد متفرقة. وزارة الزراعة واستصلاح الأراضي، نشرة احصاءات الثروة 
Abd El-Monem et al. / Archives of Agriculture Sciences Journal 3(1) 91-104, 2020.

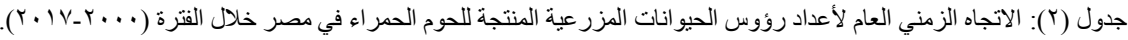

\begin{tabular}{|c|c|c|c|c|c|}
\hline معدل التغير السنوي (\%) & المتوسط & ف & ru & معادلة الإتجاه العام & البيان ان \\
\hline $1, r 7$ & $\leqslant 0 \leqslant 0, \wedge 7$ & $* * \mid \vee, \vee r$ & $\cdot, \leqslant 9$ & 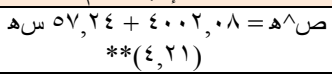 & أبقار \\
\hline - & $r v \leq \tau, V)$ & $1, Y 7$ & $\cdot, r$ & 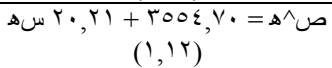 & 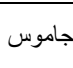 \\
\hline$\cdot, \wedge \mathrm{V}$ & $O Y \wedge \varepsilon, Y Y$ & $* * r r, \leqslant 9$ & $\cdot, 00$ & 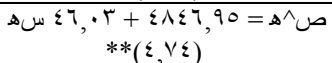 & أغنام \\
\hline$\cdot, 91$ & $\varepsilon \cdots r,+\tau$ & $* * \mid \vee, 1 \leq$ & $\cdot, \leqslant \wedge$ & 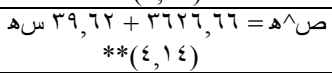 & ماعز \\
\hline- & 1 ro, ov & $r, q 1$ & $\cdot, 11$ & 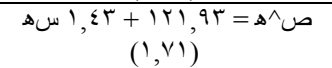 & جمال ل \\
\hline
\end{tabular}

المصدر: حسبت من: بيانات الجدول رقم (1).

نفس الجدول أن عدد رؤوس الماعز قد تذبذب بين

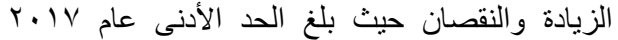

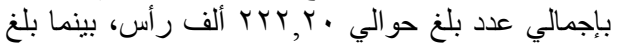

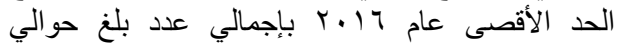

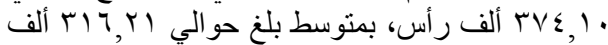

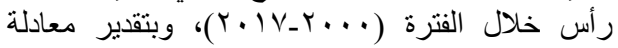

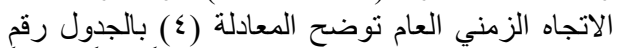
(؟)، أن عدد رؤوس الماعز قد أخذ اتجاهاً عاماً منز ايداً

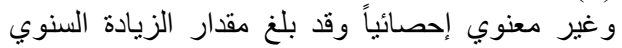

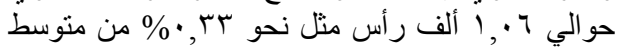

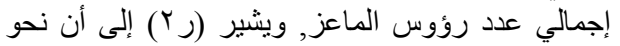

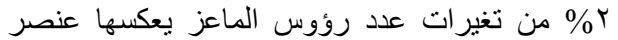

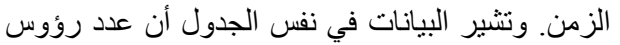

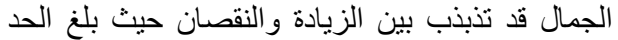

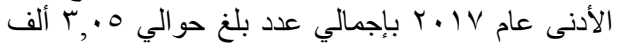

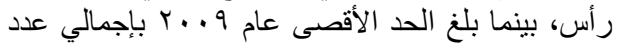

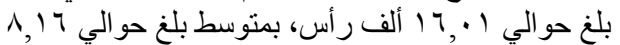

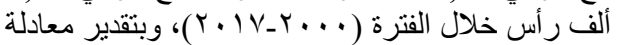

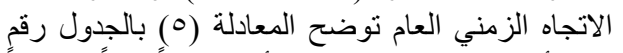

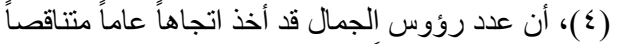
و غير معنوي إحصائياً.

\section{ثانيا: توصيف متغيرات مشروعات تسمين الأبقار في عينة البحث بمحافظة أسيوط أتوطيف مئرو}

يبين الجدول (0) مدى الاختلاف في المتوسطات الموردية للفئات الانتاجية الثلاثة، حيث بلغ عدد الإن الحيو انات للفئة الانتاجية

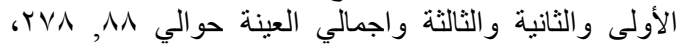

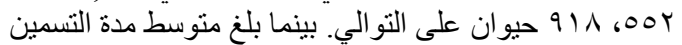

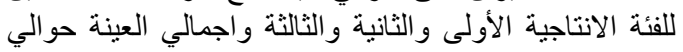

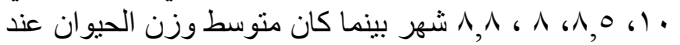

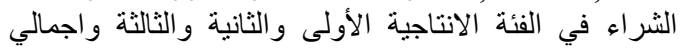

r. تطور أعداد رؤوس الحيوانات المنتجة للحوم الحمراء

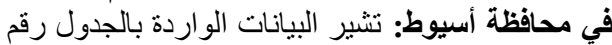

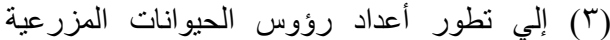

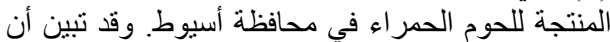

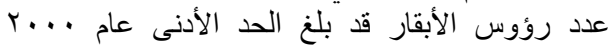

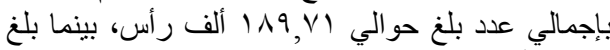

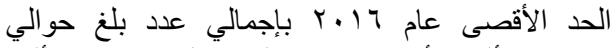

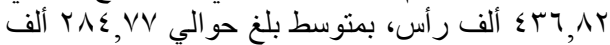

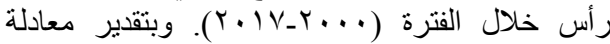

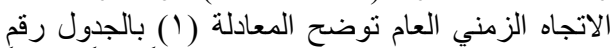
(؟)، أن عدد رؤوس الأبقار قد أخذ اتجاهاً عاماً متز ايداً

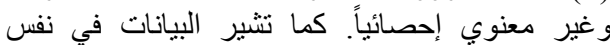

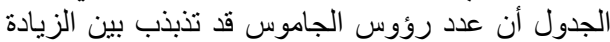

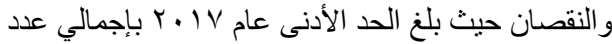

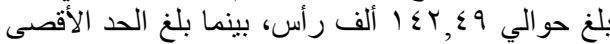

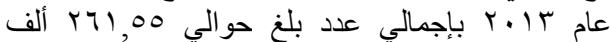

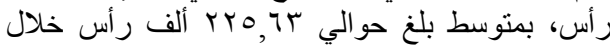

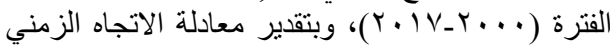

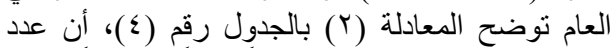

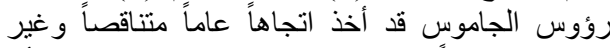

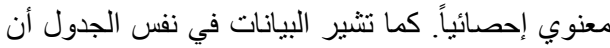

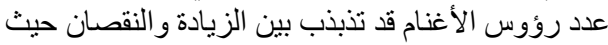

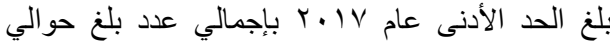

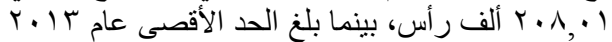

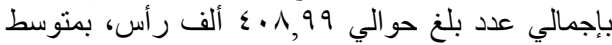

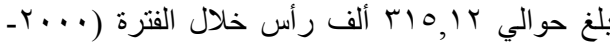
المعادلة (Y.IV

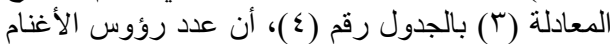

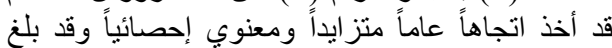

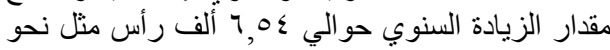

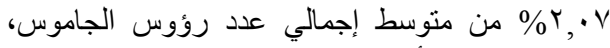

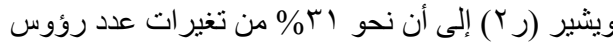

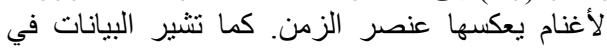




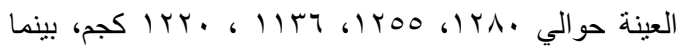

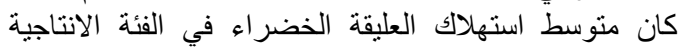

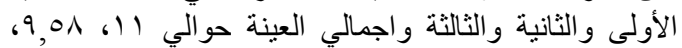

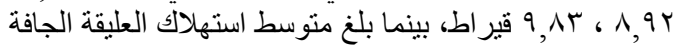

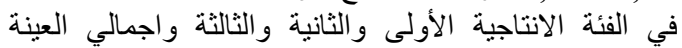

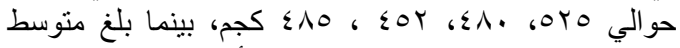

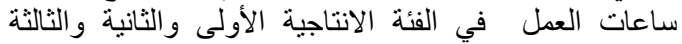

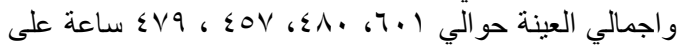

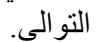

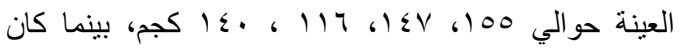

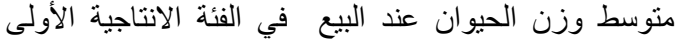

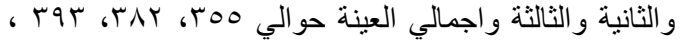


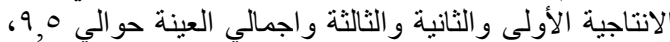

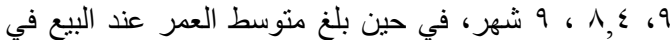

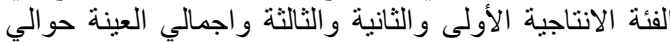

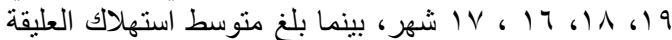

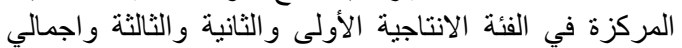

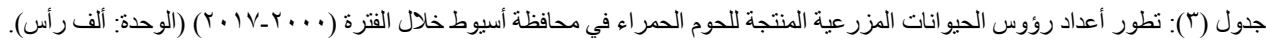

\begin{tabular}{|c|c|c|c|c|c|}
\hline جمال & ماعز & أغنام & جاموس & أبقار & السنة \\
\hline 7,71 & rTO, 10 & TVT,V & $r \cdot \Lambda, 07$ & $1 \wedge 9, \times 1$ & $r \ldots$ \\
\hline$\nabla, \Gamma \xi$ & $T V T, \leqslant 0$ & $r \leqslant 7, r V$ & $r \mid \leqslant, \cdot \varepsilon$ & Yor, 70 & $r \ldots l$ \\
\hline 7,91 & $r \wedge \cdot, \cdot 1$ & $r O \wedge, \wedge T$ & KTY,VE & $r \varepsilon \cdot, \cdot$ & $r \ldots r$ \\
\hline 7,19 & $r \wedge 0, T V$ & TY\&,1I & $r \varepsilon \cdot, T r$ & YOY,TV & 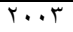 \\
\hline $7, \leqslant V$ & $r q ., 1)$ & r79,70 & $r \leqslant \leqslant, 97$ & rTT, 10 & T.. \\
\hline$v, 11$ & TYY,YT & 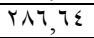 & rrq, rᄉ & $19 \cdot, \cdot 7$ & T... \\
\hline$v, r q$ & TYA, $\leqslant T$ & $r 90,+1$ & $r \leqslant r, \wedge 0$ & rqv, II & Y..T \\
\hline $11, V Y$ & rTO,TA & $r 10, r T$ & YI $\leqslant, 00$ & $r \cdot \tau, \wedge \uparrow$ & $T \ldots V$ \\
\hline $9, \leqslant 0$ & $r T \leqslant, \lambda r$ & $517,9 V$ & r17,99 & TIY,VY & $r \ldots A$ \\
\hline $17, .1$ & rrT,, 1 & $r 19,19$ & $r r q, 1 \varepsilon$ & $T V \varepsilon, V$ & $r \ldots q$ \\
\hline $1 \Gamma, \wedge T$ & $r T \leqslant, \Gamma \leqslant$ & TIV,01 & TYV, T. & $r q ., \leqslant 0$ & T.1. \\
\hline 7,10 & Tro,o. & TY,TY & $r \mid \leq, r \leqslant$ & YYะ,TY & $r .11$ \\
\hline 7,71 & rTד,Vo & $\varepsilon \cdot \vee, \wedge 0$ & YI., $9 \varepsilon$ & $r 01, \cdot V$ & 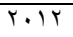 \\
\hline v,or & r9o,ro & $\varepsilon \cdot \wedge, 99$ & $Y 71,00$ & $T \leqslant Y, \wedge 0$ & $T .1 T$ \\
\hline$v, 7)$ & 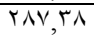 & $r 70, r 1$ & THV,70 & ror,,$\leqslant$ & $T \cdot 1 \leqslant$ \\
\hline$V, T V$ & r47,.0 & rqะ,TV & $r \leqslant \wedge, 90$ & ¿ाV,々। & $T .10$ \\
\hline$v, 7$ & $r V \leqslant, 1$. & $\varepsilon+1, V V$ & THT, & $\varepsilon r \neg, \wedge r$ & $T .17$ \\
\hline$r, \cdot 0$ & TYY,Y. & $r \cdot \wedge, \cdot 1$ & $1 \leqslant Y, \leqslant 9$ & $1 \wedge 9, \wedge \vee$ & $T . I V$ \\
\hline$\wedge, 17$ & $r 17, Y 1$ & $r 10,1 r$ & YTO,Tr & $T \wedge \varepsilon, V Y$ & المتوسط \\
\hline
\end{tabular}

العصدر: الجهاز المركزي للتعبئة العامة و الحصاء الكتاب الاحصائي السنوي، أعداد متفرقة. وزارة الزراعة واستصلاح الأراضي، نثرة احصاءات الثروة الحيوانية،

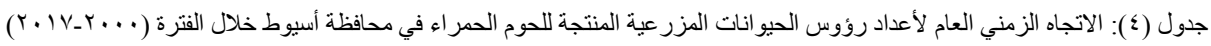

\begin{tabular}{|c|c|c|c|c|c|}
\hline معدل التغير السنوي (\%) & المتوسط & ف & זر & معادلة الإتجاه العام & اليبان \\
\hline $1, \wedge \varepsilon$ & $Y \wedge \varepsilon, V Y$ & $r, r)$ & $\cdot, 1 T$ & $\begin{array}{c}\text { ص } 0, r \varepsilon+r r \leqslant, 99-=\Delta \wedge \\
(1, \wedge 9)\end{array}$ & أبقار \\
\hline - & Yro,Tr & $\cdot, \Gamma \leq$ & $\cdot, \cdot r$ & 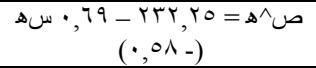 & جاموس \\
\hline$r, \cdot v$ & M10, Ir & $* \wedge, Y \vee$ & $\cdot, r$ & $\begin{aligned} ه \top, 0 \varepsilon & +r \circ r, q q=\Delta^{\wedge} ص \\
& *(r, \wedge \vee)\end{aligned}$ & أغنام \\
\hline$\cdot r$ & $r|7, r|$ & $\cdot$, ro & $\cdot, \cdot r$ & 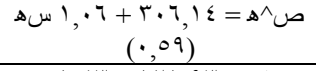 & 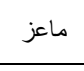 \\
\hline - & 1,17 & $\cdot, \cdot \varepsilon$ & $\cdot, \cdot r$ & 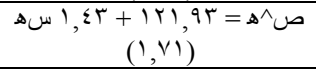 & جمال \\
\hline
\end{tabular}

المصدر: حسبت من: بيانات الجدول رقم (). 
جدول (0): المتوسطات الموردية لمشرو عات تسمين الأبقار في عينة البحث.

\begin{tabular}{|c|c|c|c|c|}
\hline اجمالي العينة & الفئة الثالثة & الفئة الثانية & الفئة الأولى & 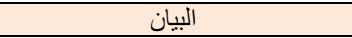 \\
\hline 911 & $00 \mathrm{r}$ & TVA & $\Lambda \Lambda$ & العدد المسمن (رأس) \\
\hline$\wedge, \wedge$ & $\Lambda$ & $\Lambda, 0$ & 1. & مدة التسمين (شهر) \\
\hline $1 \leqslant$. & 117 & $1 \leq V$ & 100 & منوسط وزن الحيو ان عند الثر اء (كجم) \\
\hline rvo & rar & rAT & roo & متوسط وزن الحيوان عند البيع (كجم) \\
\hline 9 & $\Lambda, \varepsilon$ & 9 & 9,0 & متوسط العمر عند الثراء (شهر) \\
\hline IV & 17 & 11 & 19 & متوسط العمر عند البيع (شهر) \\
\hline IKY. & 11147 & $1 Y 00$ & TrA. & متوسط العليقة المركزة (كجم) \\
\hline $9, \wedge \Gamma$ & $\lambda, 9 Y$ & 9,01 & 11 & متو سط العليقة الخضر اء (قير اط) \\
\hline$\sum 10$ & \&OY & $\varepsilon \lambda$. & OYO & متوسط العليقة الجافة (كجم) \\
\hline$\sum \vee 9$ & rov & $\sum \Lambda$. & 7.1 & متوسط ساعات العمل (ساعة) \\
\hline
\end{tabular}

المصدر: جمعت وحسبت من بيانات استمارة الاستبيان.

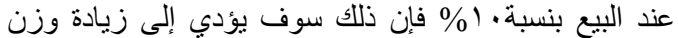

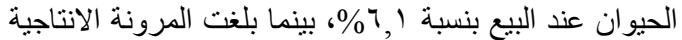

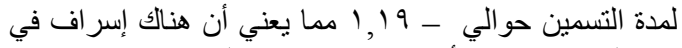

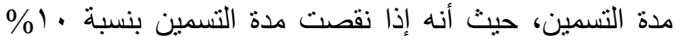

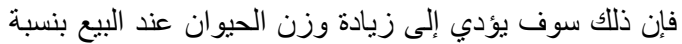

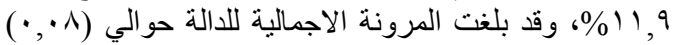

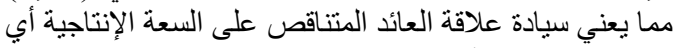
زيادة الناتج بنسبة أقل من نسبة زيادة المباد الموارد الإجمالية بالدالة.

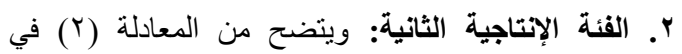

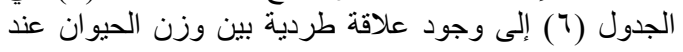

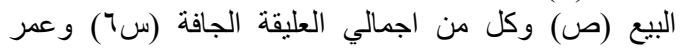

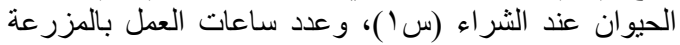

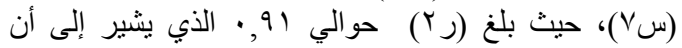

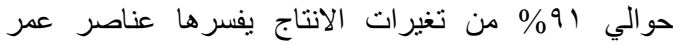

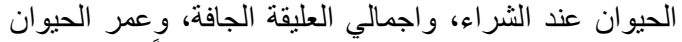

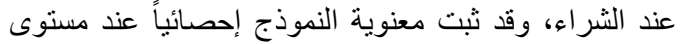
معنوية (1 +, ·)، وقد بلغت المرونة الإنتاجية لإجمالي العليقة

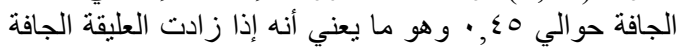

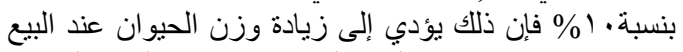

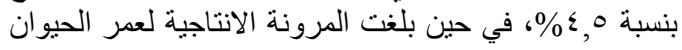

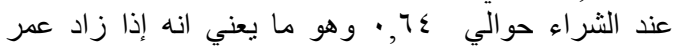

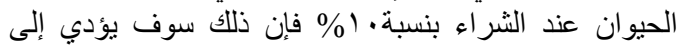

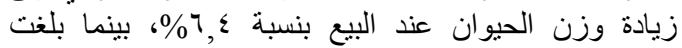

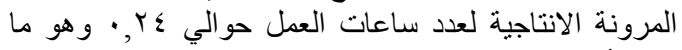

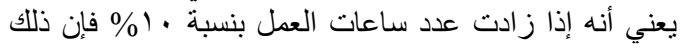

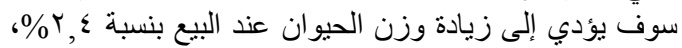

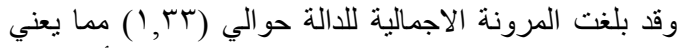

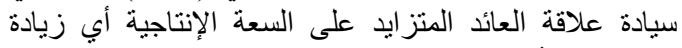
الناتج بنسبة أكبر من نسبة زيادة الموارد الإجمالية بالدالة.

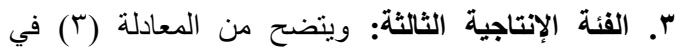
الجدول (†) إلى وجود علاقة طردية بين وزن الإنة الحيوان عند
ثالثا: الدوال الإنتاجية لمشروعات تسمين الأبقار في عينة البحث بمحافظة أسيوط

ويتناول هذا الجزء التقدير الإحصائي لدالات الإنتاج الفيزيقية

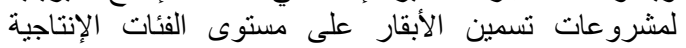

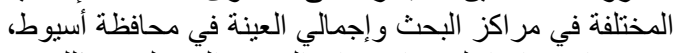

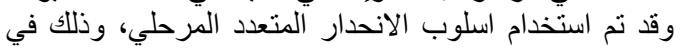

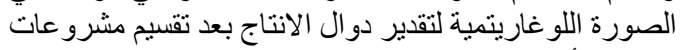

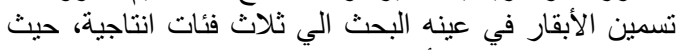

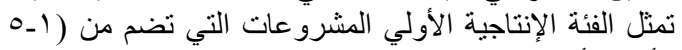

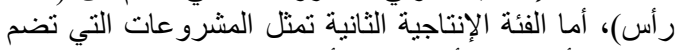

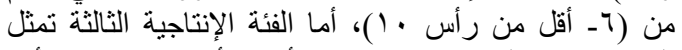

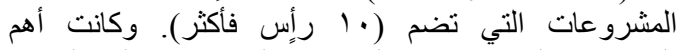

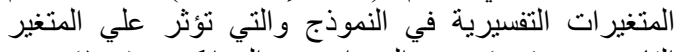

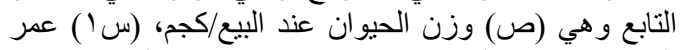

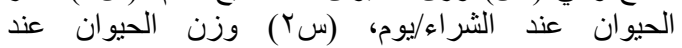

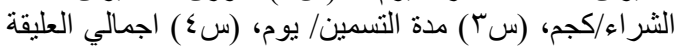

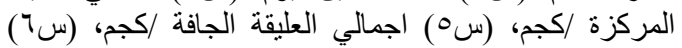

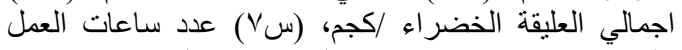

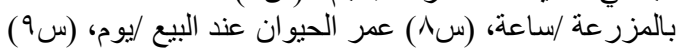
الرعاية البيطرية (متغير صوري)

أ. التقدير الإحصائي لدالات الإتتاج الفيزيقية لمشروعات

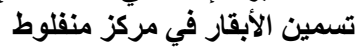

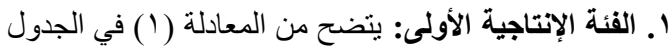

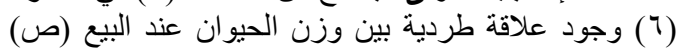

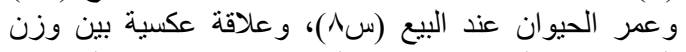

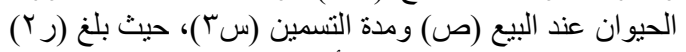

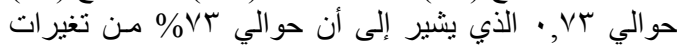

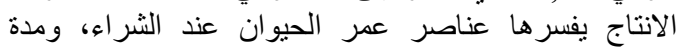

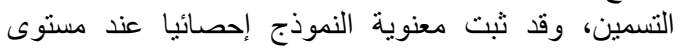

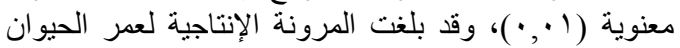

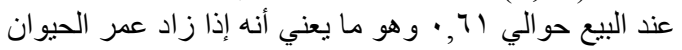




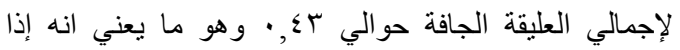

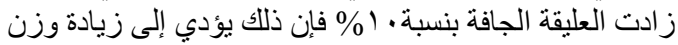

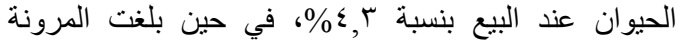

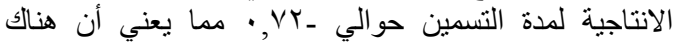

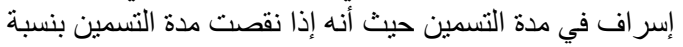

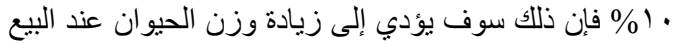

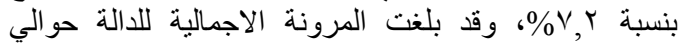

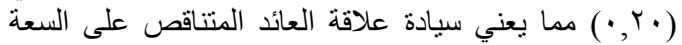
الإنتاجية أي زيادة الناتج بنسبة أقل من نسبة زيانة النيادة الموارد

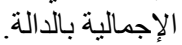

البيع (ص) وكل من اجمالي العليقة المركزة (سء) )، واجمالي

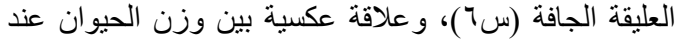

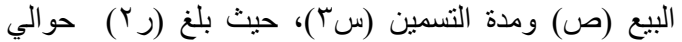

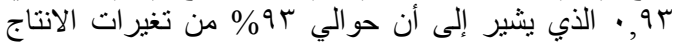

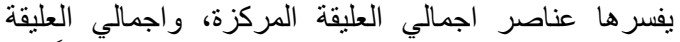

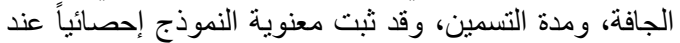

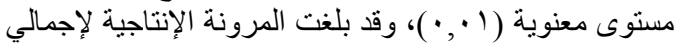

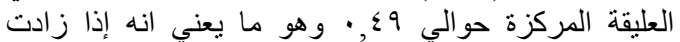

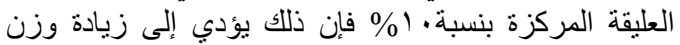

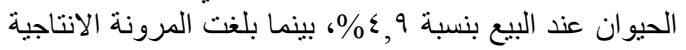

جدول (†): التقدير ات الإحصائية للدوال الإتتاجية الفيزيقية بصورتها اللوغاريتمية المزدوجة لمشرو عات تسمين الأبقار في عينة البحث.

\begin{tabular}{|c|c|c|c|c|c|}
\hline المرونة الإجمالية (\%) & ف & זر & المعادلة & الفئة الإنتاجية & المركز \\
\hline$\cdot, \cdot \wedge$ & $* * \backslash \wedge$, , & $\cdot, \mathrm{VT}$ & 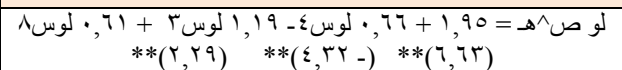 & الفئة الأولى & \multirow{4}{*}{ 毒 } \\
\hline سז, & $* * \eta \leq, r r$ & $\cdot, 91$ & 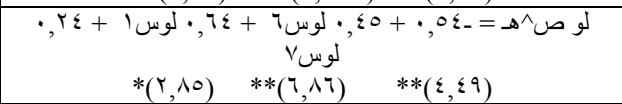 & الفئة الثانية & \\
\hline$\cdot, r \cdot$ & **人r, , & • & 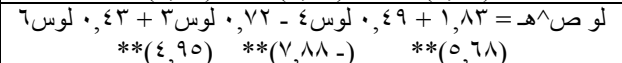 & الفئة الثالثة & \\
\hline $1,0 \leqslant$ & 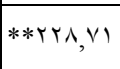 & $\cdot, 94$ & 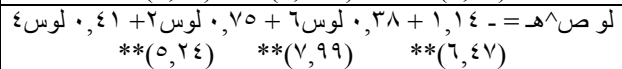 & الإجمالي & \\
\hline$\cdot, 7 \wedge$ & $* * r r, r \leq$ & $\cdot, \mathrm{V} \cdot$ & 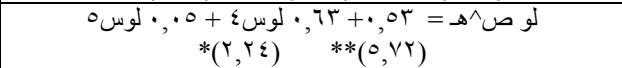 & الفئة الأولى & \multirow{4}{*}{ 司 } \\
\hline 1,10 & $* * r v \cdot, \cdot \Lambda$ & $\cdot, 9 \mathrm{~V}$ & 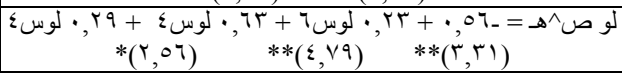 & الفئة الثانية & \\
\hline$\cdot, 97$ & $* * 1 \vee \cdot, 10$ & $\cdot, 9 \leq$ & 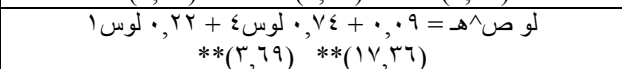 & الفئة الثالثة & \\
\hline$\cdot$, , 0 & $* * \leq \leqslant 9, \cdot 1$ & $\cdot, 97$ & 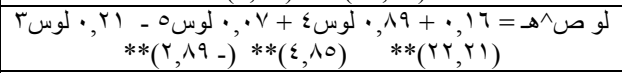 & الإجمالي & \\
\hline$\cdot, r q$ & $* * r \cdot, r \leq$ & $\cdot, 7$. & 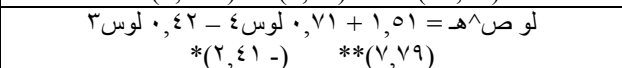 & الفئة الأولى & \multirow{5}{*}{$\begin{array}{l}\bar{j}: \\
\overline{3}:\end{array}$} \\
\hline 1,11 & $* * 1$ or, $\mathrm{r}$. & $\cdot, 94$ & 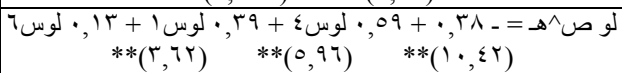 & الفئة الثانية & \\
\hline $1, \cdot 1$ & $* * 110,1 \leqslant$ & $\cdot, 19$ & 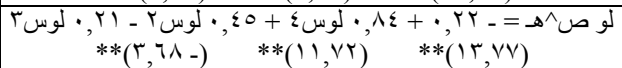 & الفئة الثالثة & \\
\hline $1,2 \leqslant 0$ & **r人ґ, & $\cdot, 91$ & 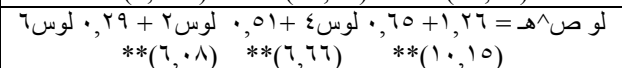 & الإجمالي & \\
\hline المرونة الإجمالية \% & ف & ru & المعادلة & الفئة الإنتاجية & \\
\hline
\end{tabular}

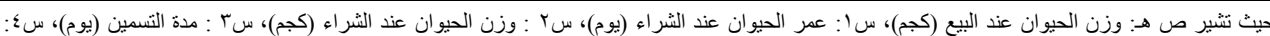

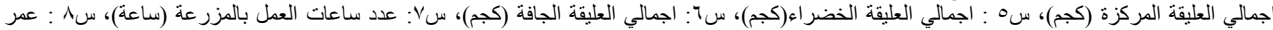

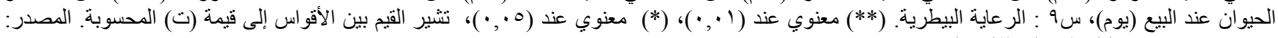
جمعت وحسبت من بيانات استمارة الاستبيان.

النموذج إحصائيا عند مستوى معنوية (1 (•, •)، وقد بلغت

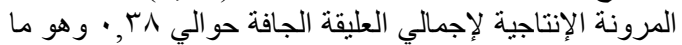

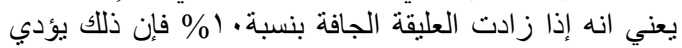

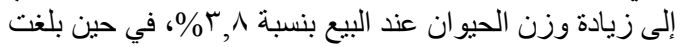

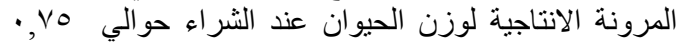

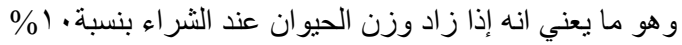
فإن ذللك سوف يؤدي إلى زيادة وزن الحيوان إن عند البيع بنسبة النية

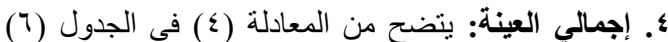

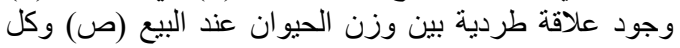

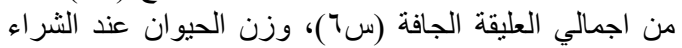

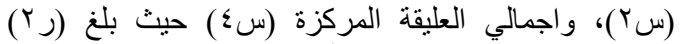

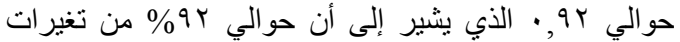

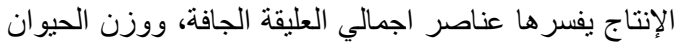

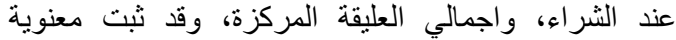


على السعة الإنتاجية أب زيادة الناتج بنسبة أكبر من نسبة زيادة الموارد الإجمالية بالدالة. الإن.

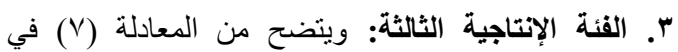

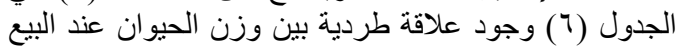

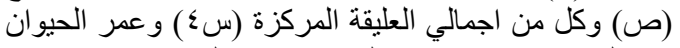

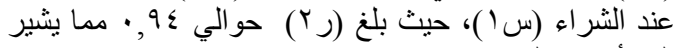

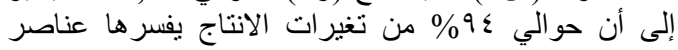

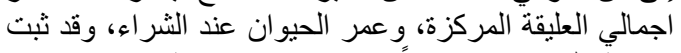

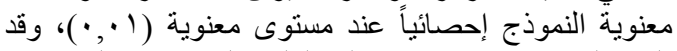

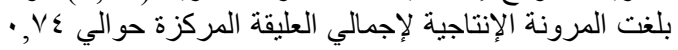

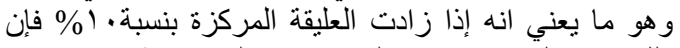

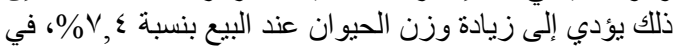

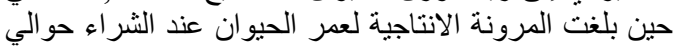

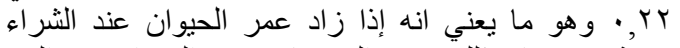

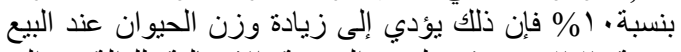

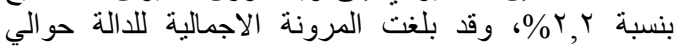

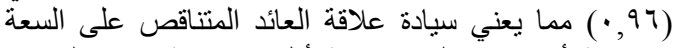

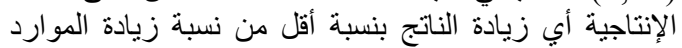

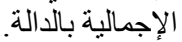

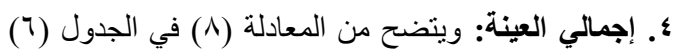

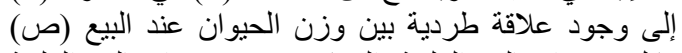

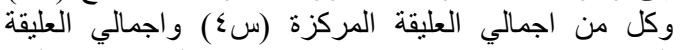

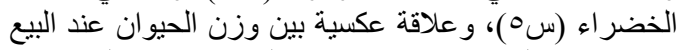

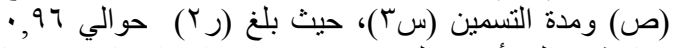

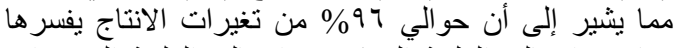

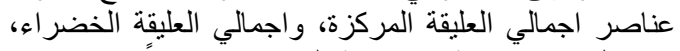

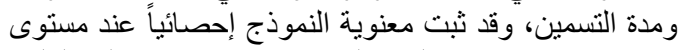

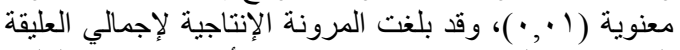

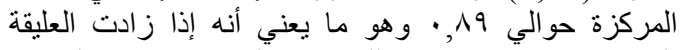

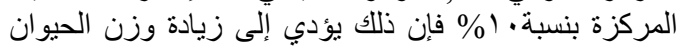

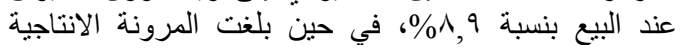

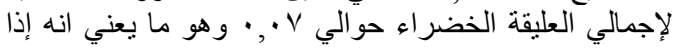

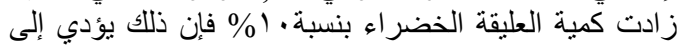

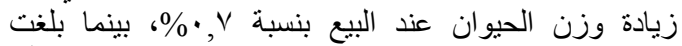

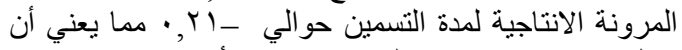

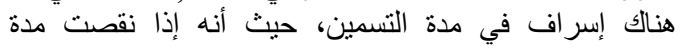

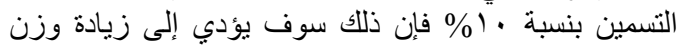

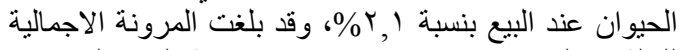

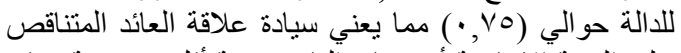

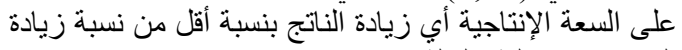

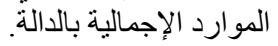

ت. التقلير الإحصائي للالات الإنتاج الفيزيقية لمشروعات تصمين الأبقار في إجمالي العينة

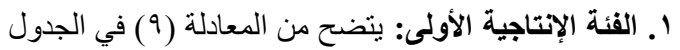

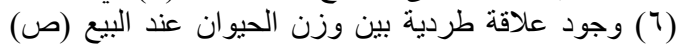

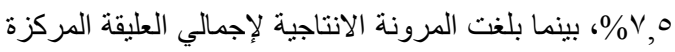

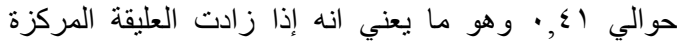

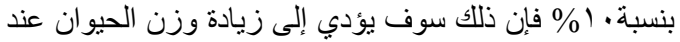

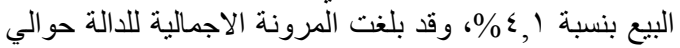

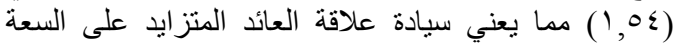
الإنتاجية أي زيادة الناتج بنسبة أكبر من نسبة زيادة العادة الموارد

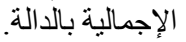

ب. التقدير الإحصائي لدالات الإنتاج الفيزيقية لمشروعات تسمين الأبقار في مركز الفتح لالاتح

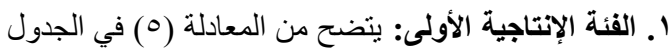

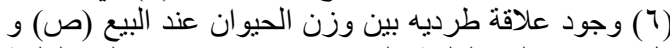

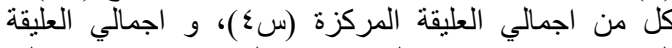

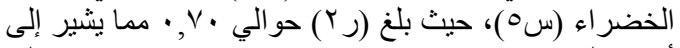

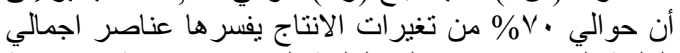

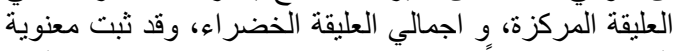

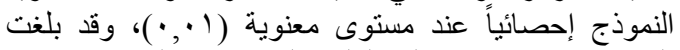

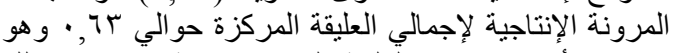

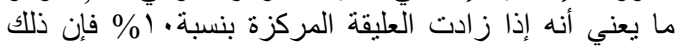

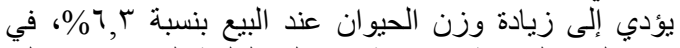

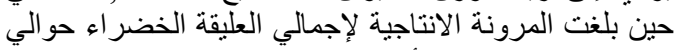

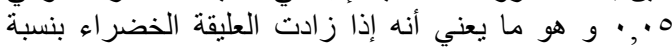

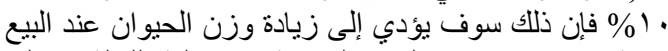

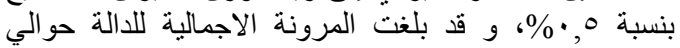

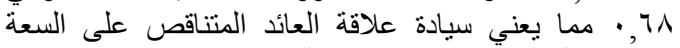

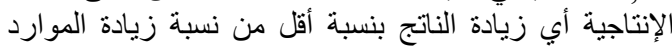
الإجمالية بالألالة.

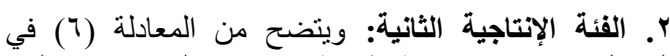

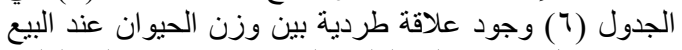

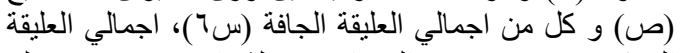

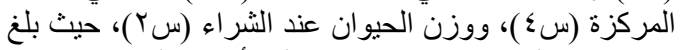

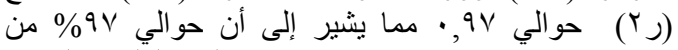

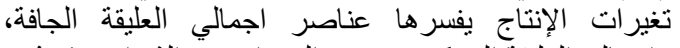

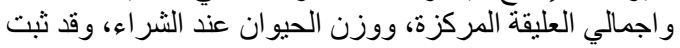

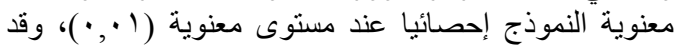

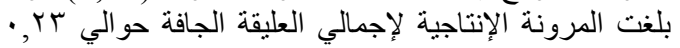

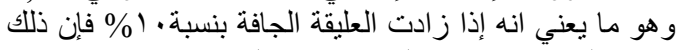

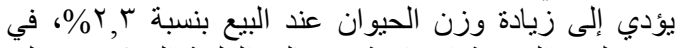

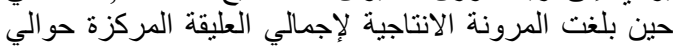

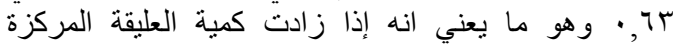

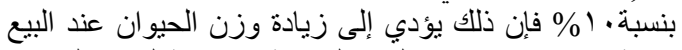

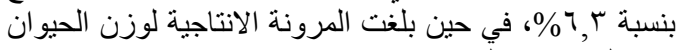

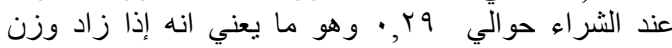

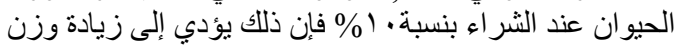

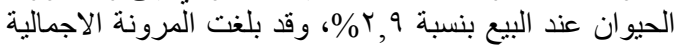
للادالة حوالي (10, (1, مما بعني سيادة علاقة العائد المتزايد 


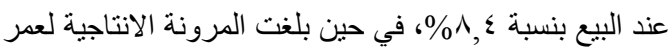

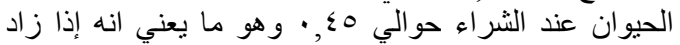

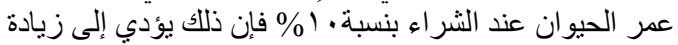

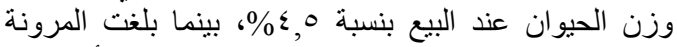

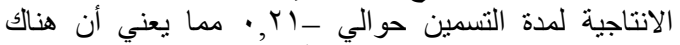

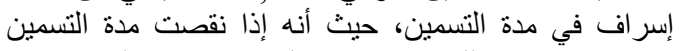

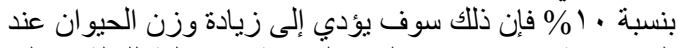

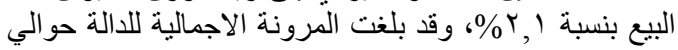

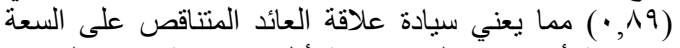

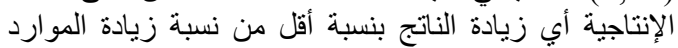

الإجمالية بالذالة.

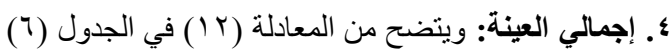

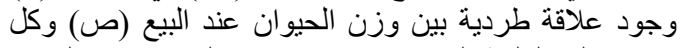

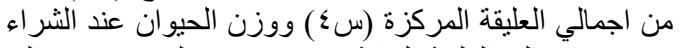

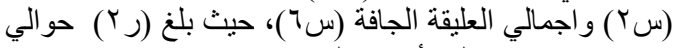

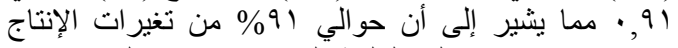

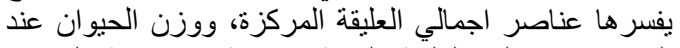

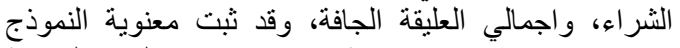

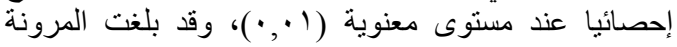

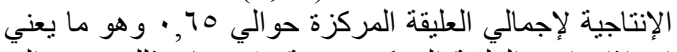

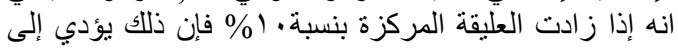

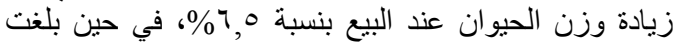

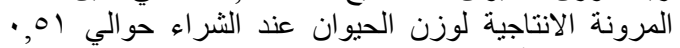

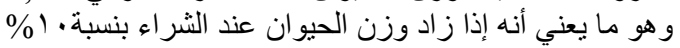

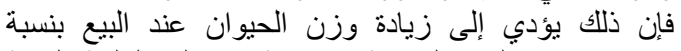

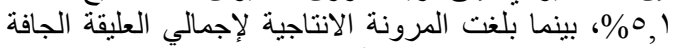

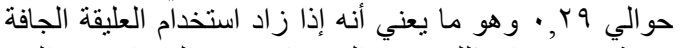

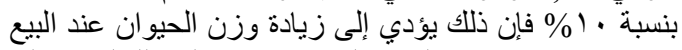

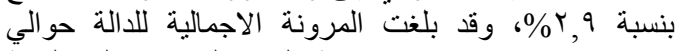

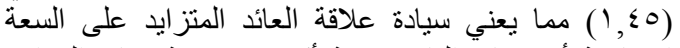

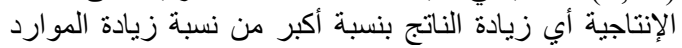

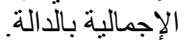

\section{رابعا: مؤشرات الكفاعة الاقتصادية لمشروعات تسمين} الأبقار في عينة البحث بمحافظة أسيوط العأفة

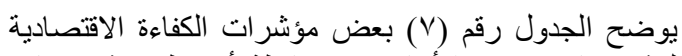

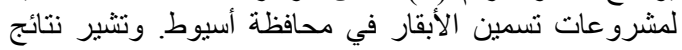

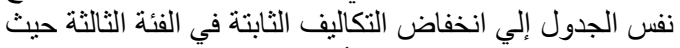

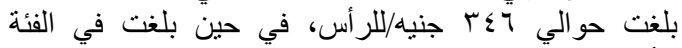

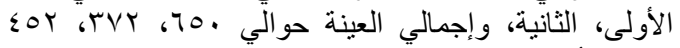

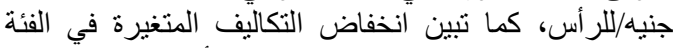

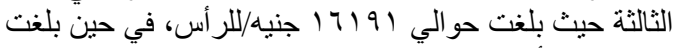

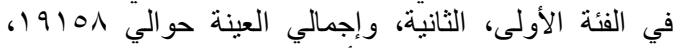

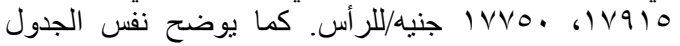

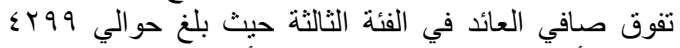

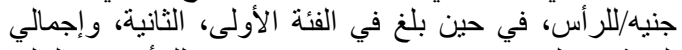

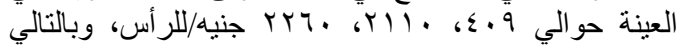

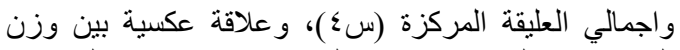

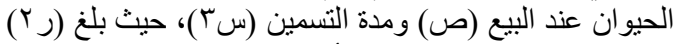

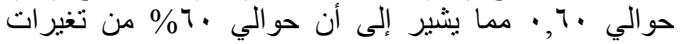

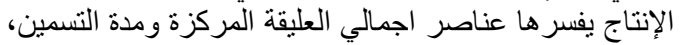

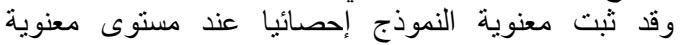

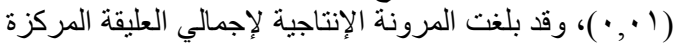

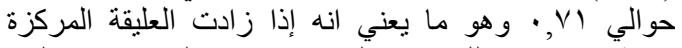

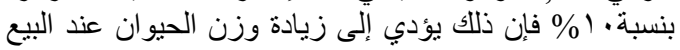

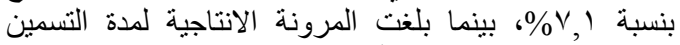

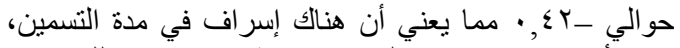

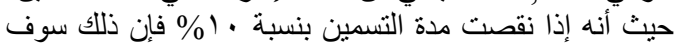

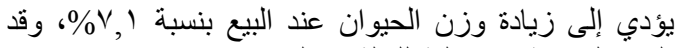

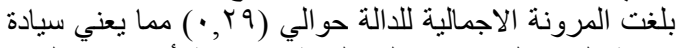

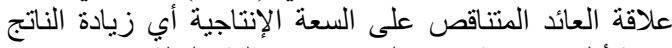
بنسبة أقل من نسبة زيادة الموارد الإجمالية بالدالة.

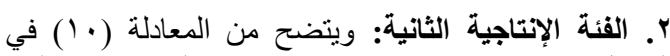

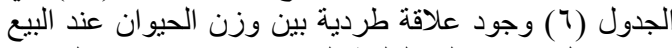

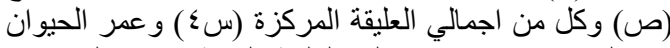

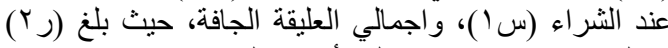

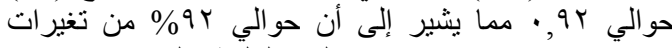

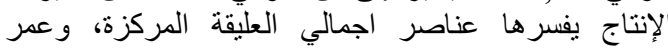

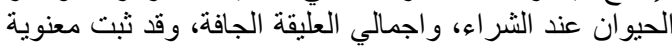

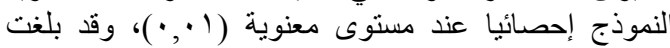

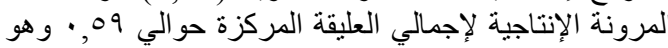

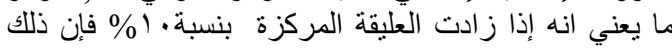

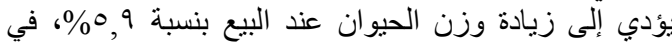

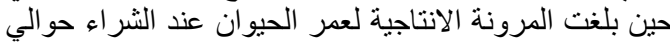

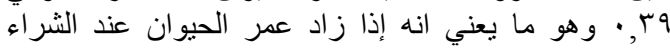

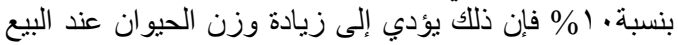

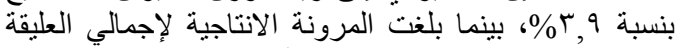

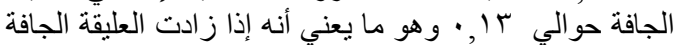

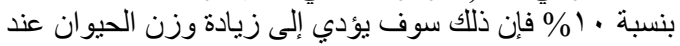

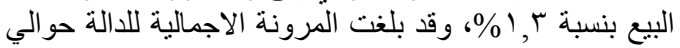

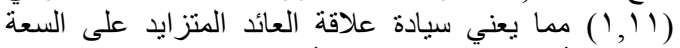

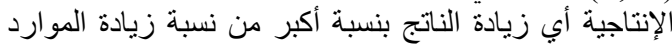

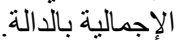

r. الفئة الإنتاجية الثالثة: ويتضح من الإله المعادلة (1) (1) في

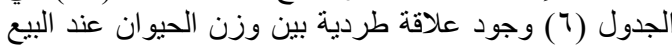

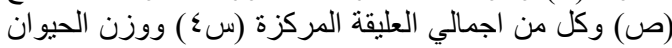

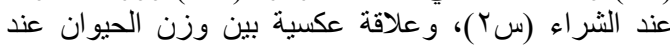

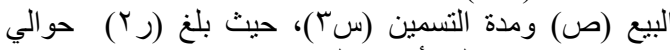

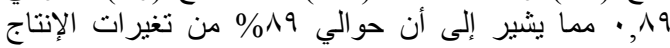

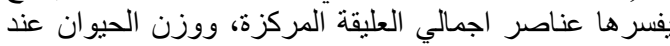

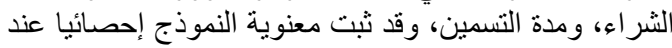

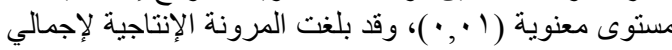

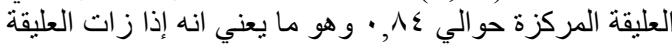

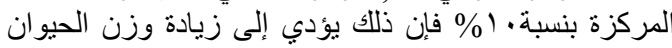




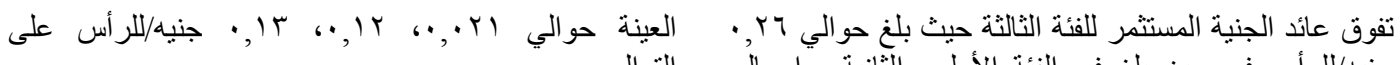

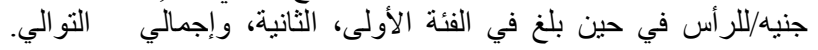

جدول (V): بعض مؤشر ات الكفاءة الاقتصادية لمشرو عات تسمين الأبقار في عينة البحث بمحافظة أسيوط.

\begin{tabular}{|c|c|c|c|c|}
\hline إجمالي العينة & الفئة الثالثة & الفئة الثانية & الفئة الاولي & 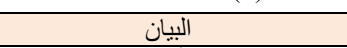 \\
\hline$\sum 0 Y$ & $r \leq 7$ & TVY & 70. & التكاليف الثابتة للر أس (بالجنيه) \\
\hline IVVO. & 17191 & 18910 & 19101 & التكاليف المتغيرة للر أس (بالجنيه) \\
\hline IAr.. & $170 \mathrm{rV}$ & IAYAV & $191 \cdot 1$ & التكاليف الكلية للر أس (بالجنيه) \\
\hline $19 V \cdots$ & $199 \cdot V$ & 19700 & 1907. & متوسط إير اد الر أس من اللحم (بالجنية) \\
\hline$V V \cdot$ & 949 & $V \leqslant Y$ & $70 \mathrm{~V}$ & قيمة الناتج الثانوي للر أس ( بالجنية) \\
\hline $\bar{r}, \varepsilon \ldots$ & Y.ATY & T. TQV & T. TIV & العائد الكلى للر أس (بالجنيه) \\
\hline
\end{tabular}

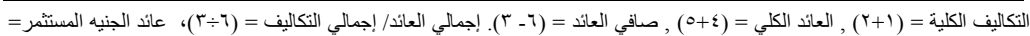

(Y)

معنوية تحليل التباين نم مقارنة الفرق المعنوي بين متوسطي

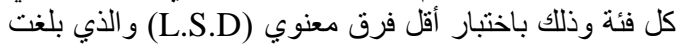

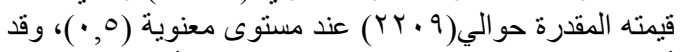

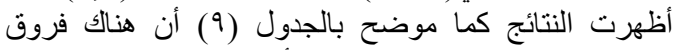
معنوية بين صافي العائد للفئة الأولى وصافي (و) الفي العائد للفئة

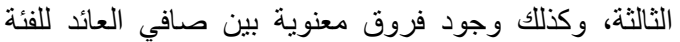
الثنانية وصافي العائد للفئة الثالثة.

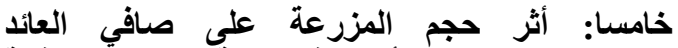 لمشروعات تسمين الأبقار في عينة البحث بمحافظة أسيوط}

يوضح الجدول (^) نتائج تحليل التباين لاختبار أثر حجم العافي

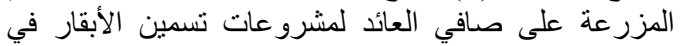
عينة البحث في محافظة أسيوط. حيث اتضح أنه بناءً على فئ فئ

جدول (^): تحليل التباين لاختبار أثر حجم المزرعة على صافي العائد لمشروعات تسمين الأبقار في عينة البحث بمحافظة أسيوط.

\begin{tabular}{|c|c|c|c|c|}
\hline المحسوبة & متوسط مجموع مربعات الانحر افات & مجموع مربعات الانحر افات & 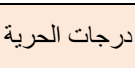 & مصدر الاختلاف \\
\hline \multirow{3}{*}{$* 1 r, \wedge \Lambda$} & V7V0.79V70 & 1040.149049 & $\bar{r}$ & بين الفئات \\
\hline & 090994071 & $79 \mathrm{VT} / 1$ Y9017 & $11 \mathrm{~V}$ & داخل الفئات \\
\hline & & $10.11 \times 79117$ & 119 & المجموع الكلي \\
\hline
\end{tabular}

جدول (9): معنوية الفروق بين صافي العائد للفئات الانتاجية لمشرو عات تسمين الأبقار في عينة البحث بمحافظة أسيوط.

\begin{tabular}{|c|c|c|c|c|}
\hline الأولى & الثانية & الثالثة & \multirow[b]{2}{*}{ المتوسطات } & \multirow{2}{*}{ الفئة الانتاجية } \\
\hline $1 \leqslant 9 . r$ & $\mid r V \Omega 1$ & $r V \vee \varepsilon 1$ & & \\
\hline \multirow[t]{3}{*}{ صفر } & YITY & *YKATA & $1 \leqslant 9 . r$ & الأولى \\
\hline & صفر & *ro... & $\mid r V \leqslant 1$ & الثانية \\
\hline & & صفر & $r V \vee \Sigma 1$ & الثالثة \\
\hline
\end{tabular}

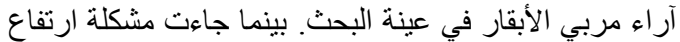

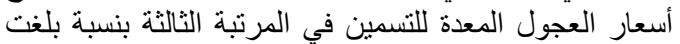

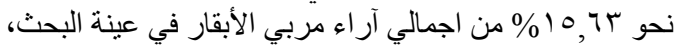

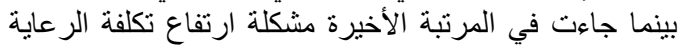

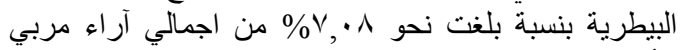

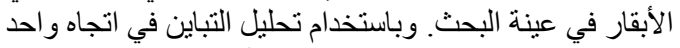

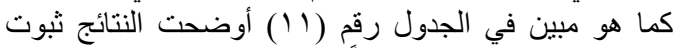

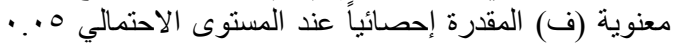

\section{سادسا: المشاكل التي تواجه مشروعات تسمين الأبقار في عينة البحث بمحافظة أسيوط هُ المبرو}

يوضح جدول (•) (1) أن مشكلة انخفاض صافي العائد أهم

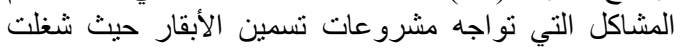

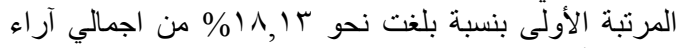

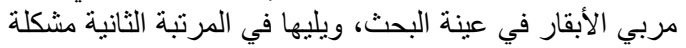

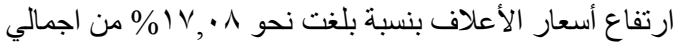




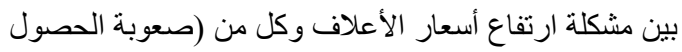

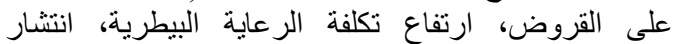

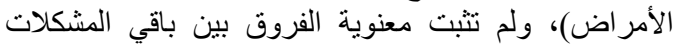

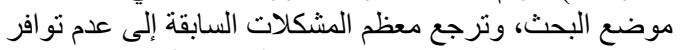

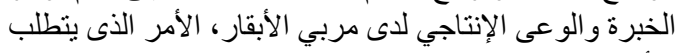

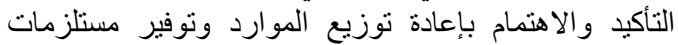

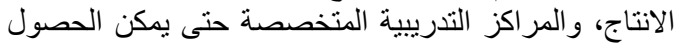
على أكبر قدر ممكن من الإنتاج حتى يمكن تعظيم ربح المنتج .
ويعنى ذللك وجود فروق معنوية بين المشكلات الإنتاجية التي

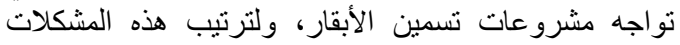

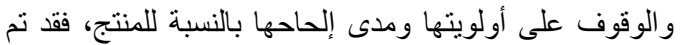

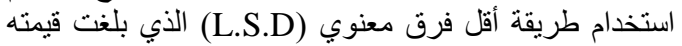

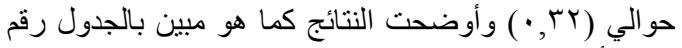

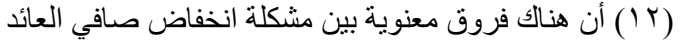

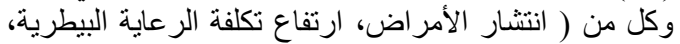

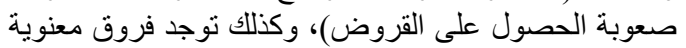

جدول (· ( ): المشاكل التي تو اجه مشرو عات تسمين الأبقار في عينة البحث بمحافظة أسيوط.

\begin{tabular}{|c|c|c|}
\hline$\%$ & عدد & نوع المشكلة \\
\hline $1 V, \cdot 1$ & Ar & ارتفاع أسعار الاعلاف \\
\hline $1 \varepsilon, 17$ & 71 & ارتفاع أجور العمالة المؤجرة \\
\hline 10,74 & vo & ارتفاع أسعار العجول المعدة للتسمين \\
\hline 11,14 & NV & انخفاض صافي العائد \\
\hline$\checkmark, 9 Y$ & ri & صعوبة الحصول علي القروض و عدم كفايتها \\
\hline $\mathrm{v}, \cdot 1$ & $r \varepsilon$ & ارتفاع تكلفة الرعاية البيطرية \\
\hline ג, r & $\varepsilon \cdot$ & انتثار الأمر اض \\
\hline $11,7 \mathrm{~V}$ & 07 & صعوبة التسويق \\
\hline $1 \cdots$ & ¿^. & الاجمالي \\
\hline
\end{tabular}

المصدر : جمعت وحسبت من بيانات استمارة الاستبيان.

جدول (1 (1): نتائج تحليل التباين للمشاكل التي تو اجه مشرو عات تسمين الأبقار في عينة البحث بمحافظة أسيوط.

\begin{tabular}{|c|c|c|c|c|}
\hline (ف) ) المحسوبة & متو سط مجموع مربعات الانحر افات & مجموع مربعات الانحر افات & درجات الحرية & مصدر الاختلاف \\
\hline \multirow{3}{*}{$* \|, I V$} & $r, 01$ & $\mid 1,11$ & V & بين الفئات \\
\hline & $\cdot, Y^{\top}$ & YY.,TI & $90 Y$ & داخل الفئات \\
\hline & & YYA,VY & 909 & المجمو ع الكلى \\
\hline
\end{tabular}

المصدر : جمعت وحسبت من بيانات استمارة الاستبيان.

جدول (r ( )): معنوية الفروق بين المشاكل التي نو اجه مشرو عات تسمين الأبقار في عينة البحث بمحافظة أسيوط.

\begin{tabular}{|c|c|c|c|c|c|c|c|c|c|}
\hline $\mathrm{X} 8$ & $\mathrm{X} 7$ & X6 & $\mathrm{X} 5$ & $\mathrm{X} 4$ & X3 & $\mathrm{X} 2$ & $\mathrm{X} 1$ & \multirow[b]{2}{*}{ المتوسطات } & \multirow{2}{*}{ المشكلات الانتاجية } \\
\hline$\cdot, \leqslant V$ & $\cdot \vec{\mu}$ & $\cdot, r 4$ & $\cdot, T_{T}$ & $\cdot, \mathrm{Vr}$ & $\cdot$ & $\cdot, 70$ & $\cdot, 7 \wedge$ & & \\
\hline \multirow[t]{8}{*}{ صفر } & $\cdot, 1 \varepsilon_{-}$ & $\cdot, 11-$ & $\cdot, 10_{-}$ & $\cdot, Y T$ & $\cdot, \pi$ & $\cdot, Y \mu$ & $\cdot, r^{\prime}$ & $\cdot, \leqslant V$ & $\mathrm{X} 8$ \\
\hline & صفر & $\cdot, \cdot r$ & $\because \cdot 1-$ & ${ }^{*} \cdot, \leqslant 1$ & $\cdot, \mu$ & $\cdot, K \mu$ & ${ }^{*} \cdot r_{0}$ & $\cdot, \pi \mu$ & $\mathrm{X} 7$ \\
\hline & & صفر & $\cdot, \cdot \varepsilon_{-}$ & ${ }^{*} \cdot, r V$ & $\cdot, Y V$ & $\cdot, Y_{1}$ & ${ }^{*} \cdot, r Y$ & $\cdot, r 7$ & $\mathrm{X} 6$ \\
\hline & & & صفر & $\cdot, \leqslant 1$ & $\cdot, \Gamma$ & $\cdot, r \xi$ & $*, r 4$ & $\cdot, r Y$ & $\mathrm{X} 5$ \\
\hline & & & & صفر & $\cdot, 1-$ & $\cdot, 1 V_{-}$ & $\cdot, \cdot 0_{-}$ & $\cdot, \mathrm{VT}$ & $\mathrm{X} 4$ \\
\hline & & & & & صفر & $\cdot, \cdot V_{-}$ & $\cdot, \cdot 0$ & י, & X3 \\
\hline & & & & & & صفر & $\cdot, 1 Y$ & $\cdot, 70$ & $\mathrm{X} 2$ \\
\hline & & & & & & & صفر & .71 & $\mathrm{X} 1$ \\
\hline
\end{tabular}

المصدر: جمعت وحسبت من بيانات استمارة الاستبيان.

؛. . الاستفادة من الأراضي المستصلحة في توفير

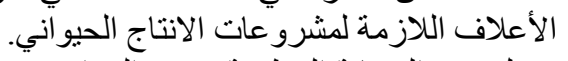

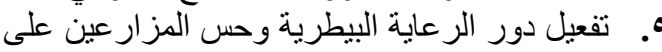
المتابعة الدورية المستمرة.
ا . زيادة الاستثمارات الموجهة لقطاع الانتاج

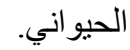
r. العمل على توفير مستلزمات الانتاج بأسعار مناسبة، ودعم المنتجين للاستمرار في عملية الاتناج باتعار 
ديوان عام محافظة أسيوط ، نشرة مركز المعلومات ودعم

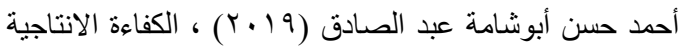

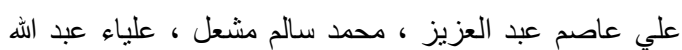

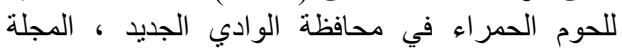

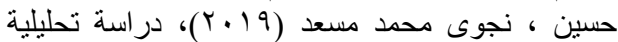

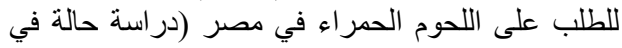

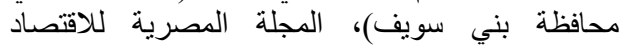

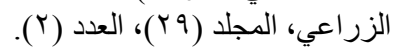

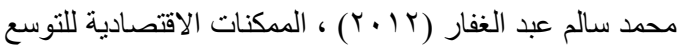

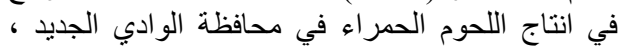

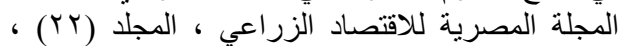

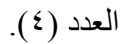

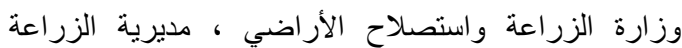
بأسيوط ، قسم الانتاج الحيو اني ، بيانات غير منشورة

المصرية للاقتصاد الزر اعي ، المجلد (ج) ) ، العدد (r).

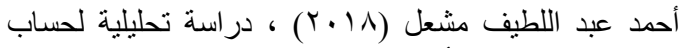

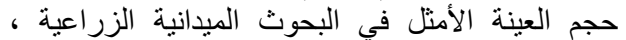

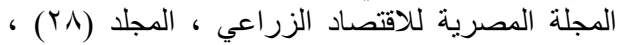
و العدد (r). ( )

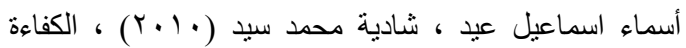

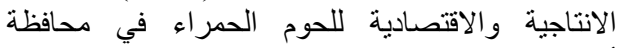

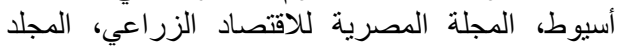

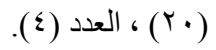

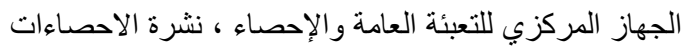
الحيوانية ، نشرة حركة التجارة الخارجية ، أعداد الادئ

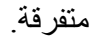

